\title{
ECHOES OF THE HOLOCAUST IN LEONARD COHEN'S ART
}

\author{
KAROLINA ADAMSKICH
}

\begin{abstract}
Leonard Cohen is mostly known as a singer-songwriter. Although his poems and novels are not as widely recognized as his music, it has been frequently argued that The Favourite Game (1963) and Beautiful Losers (1966) can be viewed as the most innovative and experimental novels to be published in Canada. They are also among the first representatives of Canadian postmodernism in literature. The main purpose of this article was to explore echoes of the Holocaust in Cohen's novels, as well as in his book of poetry Flowers for Hitler (1964). Despite the fact that the links and allusions to Judaism made by him have been often stressed by the critics, what is demonstrated here is the fact that for Cohen, his Jewish heritage was not only a source of inspiration but also doubt and anger. This paper, apart from presenting the artist's cultural and spiritual background, aims at demonstrating ethical ambivalences in Leonard Cohen's art and examining the reasons behind the ambivalence, as well as discussing his works in the context of postmodern ethical theory.
\end{abstract}

Key words: Leonard Cohen, the Holocaust, contemporary Canadian literature, postmodern ethics

Leonard Cohen began his career in 1956 with the publication of his first book of poetry, Let Us Compare Mythologies. By the end of the 1960s, Cohen had been already the author of three other collections of poems, as well as two novels, The Favourite Game (1963) and Beautiful Losers (1966). At the same time, disappointment with the financial side of his literary career pushed Cohen to music composition. In 1967, the first studio album, Songs of Leonard Cohen, was released, followed by his first public performance. Although his poems and novels are not as widely recognized as his music, it has been frequently argued that Beautiful Losers can be viewed as one of the most innovative and experimental novels to be published in Canada, as well as one of the first representatives of Canadian 
postmodernism in literature. As for his music, Cohen has enjoyed commercial and critical acclaim worldwide, with his song lyrics being translated into numerous languages.

Although Cohen has been acknowledged as a poet exploring the themes of religion and spirituality since the beginnings of his career in the late 1950s, his works have been frequently analysed only from a limited perspective. So far, the fact of his art being ethically ambiguous has been to a large extent ignored, with critics commenting mostly upon his links with Jewish heritage or experimentation with Zen Buddhism. Thus, this study aims to present Cohen as an artist who creates his own ethical system by synthesizing the postmodern ethical theory with the elements borrowed from different spiritual systems and beliefs, including Judaism, Christianity, Buddhism, Native American mythologies and pagan imagery.

Furthermore, it was during the 1960s that the Holocaust started to be an openly discussed topic. This change, undoubtedly, influenced the works of many writers of Jewish origin, one of them being Leonard Cohen._The main purpose of this paper was to explore echoes of the Holocaust in Leonard Cohen`s art. Although his Jewish heritage has been frequently perceived as a source of inspiration, this article, apart from presenting the artist's cultural and spiritual background, aims at demonstrating ethical ambivalences of Leonard Cohen's art and examining the reasons behind the ambivalence, as well as discussing his works in the context of postmodern ethical theory.

\section{Consequences of the Holocaust for the Jewish community}

Understandably, the Holocaust is seen as a turning point and an unprecedented event in Jewish history, inasmuch as it resulted in the murder of almost six million European Jews (Neusner 2006: 172) and, as a consequence, in erasing of the Eastern-European Jewish communities, along with their culture and heritage (Lang 2007: 281). It can be also argued that the emergence of the State of Israel was indirectly caused by the Holocaust as well. From a moral and psychological perspective, the extermination of the Jews on a mass scale resulted in the "rupture in the postHolocaust moral universe - a transformation in moral conscience and consciousness" (Lang 2007: 279). The aftermath of the extermination, as well as the Holocaust itself, however, was not an openly discussed issue until the 1960s; on the contrary, up to this time "the shadow of the Nazi death camps was an ever present but virtually unacknowledged background to Jewish life and belief in Europe, Israel, and North America" (Morgan and Gordon 2007: 10). During the 1960s, when the studies concerned with the issue of the Holocaust started to gain prominence, the speculations began as for the reasons and purpose of its occurrence.

On the one hand, it has been argued among the Jewish philosophers that the Holocaust realizes "[t]he ancient pattern of exile and return", meaning that the 
extermination of the Jews on the continent and demolishing the centres of Jewish communities was redeemed by "the restoration of Israel to the Land of Israel and creation of the State of Israel" (Neusner 2006: 172). According to this hypothesis, the Holocaust can be seen as a tragic but not completely destructive and pointless event, inasmuch as without it, Israel as an independent country would not have been created (Lang 2007: 285). The concept of exile is inextricably connected with the second hypothesis concerning the purpose behind the suffering of the Jews, namely that of divine punishment. Wassermann (1952, as quoted in Lang 2007: 283), for instance, argued that "[i]n those [pre-Holocaust] days, the Jews chose for themselves two forms of idolatry, (...) socialism and nationalism. A miraculous event occurred: in Heaven the two idolatries were combined into one - National Socialism". Also Neusner (2006: 175) stresses the fact that the concept Jahwe's punishment resulting in suffering and exile is an ubiquitous motif in Jewish liturgy and philosophy: "Prior calamities, from ancient Israelite times forward, precipitated self-incrimination: "On account of our sins we have been exiled from our land" expresses the norm, and makes its appearance in the Sabbath liturgy". The Holocaust has been also presented as an analogy to the 'binding' of Isaac in the Bible, where Abraham's sacrifice of his own son is treated as a test of faith and, similarly, the Holocaust is supposed to be interpreted as a test as well (Lang 2007: 286).

Such views, however, have been strongly criticized by some, insofar as it can be also assumed that a person is granted, first and foremost, free will. Therefore, it is an individual who is responsible for their fate and God does not play any role in the unraveling of the history:

Acting on his own, man rather than God becomes responsible for whatever evil occurs in human history (...). Given God`s benevolence and omnipotence, evil - when it does occur - inflicting suffering and loss on the innocent - expresses human, not divine, character and choice (...). Human freedom must be respected by God himself. God cannot as a rule intervene whenever man`s use of freedom displeases him (Lang 2007: 284).

It has been also stressed that the attempts at explaining and discussing the Holocaust exclusively in the context of the Jewish history may be dangerous, since, as Bauman (1989: 1) puts it, "present[ing] the Holocaust as something that happened to the Jews [and] as an event in Jewish history makes the Holocaust unique, comfortably uncharacteristic and sociologically inconsequential". Also according to Emmanuel Levinas, one of the most influential Jewish thinkers, the Holocaust should be presented "as a 'paradigm' of suffering" and "parallel to the Gulag and all other places of suffering in our political century - in other words, part of a broader, (...) non-specific, historical tendency" (1998, as quoted in Lang 2007: 289). It can be argued that it is exactly in this way that the Holocaust has been portrayed in Cohenąs works, as it will be presented later. 
The post-Holocaust period was marked by changes in Jewish spirituality and lifestyle. After the Second World War, Jewish survivors and their families frequently chose North America as their final destination; the centres and institutions of the Jewish community, thus, thrived and became widespread. The social revolution that began in the 1960s, in addition, resulted in the growing interest in counter-culture and alternative forms of spirituality, such as various Eastern religions, meditation and mysticism (Salkin 2004: 366f.). These changes were reflected also within the Jewish communities, with the Orthodox Judaism becoming overshadowed by this new, eclectic form of spirituality. This phenomenon, known as Jewish Renewal, was followed by borrowings from various religions and wisdom traditions, for instance Hinduism, Buddhism, Christianity and the branch of Islamic mysticism known as Sufism, but also, interestingly, from ancient paganism and the New Age (Salkin 2004: 368). As Salkin (2004: 367) also points out, according to the teachings of this more contemporary form of Judaism, "all spiritual paths are similar and (...) all spiritual wisdom is interchangeable". As for the tenets of Judaism itself, it has been observed that the rituals and ideas that are seen as close to the Eastern and New Age traditions became more popular. Among them were, most importantly, the Kabbalah, which is a branch of Jewish mysticism, as well as the belief in "the female face of divinity", Shekhinah, who is believed to be the female embodiment of Jahwe and who resembles the goddesses of the religions of the East (Salkin 2004: 372). All of these fluctuations and ideas can be ultimately traced in Cohen's works; however, despite the fact that, as Salkin (2004: 369) argues, the emergence of this new current of Judaism may be seen as a natural process, inasmuch as "[a]11 historic Judaisms have borrowed from the majority culture", it can be also viewed as a negative phenomenon which, instead of enriching Jewish spirituality, turns it into an empty and superficial construct.

Without doubt, the Holocaust can be seen as the point in history that changed the perception of the contemporary civilization and posed questions on the state of humanity as a whole. Most importantly, as it has been already mentioned, it has been stressed that the Holocaust should not be perceived as an issue concerning only the Jewish community but, on the contrary, as an event pointing at the failure of the systems of the contemporary Western society (Bauman 1989: 13). The Holocaust has been even called "the most demonic expression of modernity" (Gillman 2004: 456), insofar as it was the modern, rational world that created the suitable conditions for the extermination to be conducted. As Bauman (1989: 83) points out, "[o]ur evolution has outpaced our understanding; we can no longer assume that we have a full grasp of the workings of our social institutions, bureaucratic structures, or technology". Also Gillman (2004: 456) stresses the fact that the post-Holocaust period is characterized by disillusionment as far as the reliability of human reason, science or technological advance is concerned: 
If modernity exhibited a basic confidence in our ability to understand and control the world, a reliance on science and technology and on unbridled confidence in human reason as the most sublime expression of our humanity, postmodernism implies the very opposite. It emphasizes a new humility about human power, a vision of science as resting on arbitrary foundations, and a recognition of the limits of reason as a resource for dealing with the most significant dimensions of human experience.

Apart from discrediting the working of the modern society, the fact that the Holocaust could happen in a seemingly civilized society resulted in the ideas on which the contemporary Western world relies being questioned. First of all, as Bauman (1989: 92) argues, the accurate name for the modern culture is "a garden culture", inasmuch as it strives toward a perfect society from which certain groups or individuals that do not fit can be eliminated:

Some gardeners hate the weeds that spoil their design - the ugliness in the midst of beauty, litter in the midst of serene order. Some others are quite unemotional about the: just a problem to be solved (...). Modern culture is a garden culture. It defines itself as the design for an ideal life and a perfect arrangement of human conditions.

What is more, the Western world tends to perceive itself as superior to other, more "primitive" and less technologically advanced societies. Thus, acts of aggression perpetuated towards these seemingly inferior cultures or countries are not seen as unfounded at all; on the contrary, they are often portrayed as a necessary effort to free the world from the abnormalities and barbarism that endanger the "superior" cultures. As Bauman (1989: 96) states: "Western civilization has articulated its struggle for domination in terms of the holy battle of humanity against barbarism, reason against ignorance, objectivity against prejudice, progress against degeneration, truth against superstition, science against magic, rationality against passion". All of this suggests a dispassionate and almost scientific approach, as the mass murder of the Jews or Gypsies was not really motivated by truly pragmatic reasons, like for instance the conflict over a given territory or the one inspired by the ideological or religious issues. On the contrary, "Stalin's and Hitler's victims (...) were killed because they did not fit, for one reason or another, the scheme of a perfect society. Their killing was not the work of destruction, but creation" (Bauman 1989: 92). Paradoxically, it can be argued that it was this emotionless approach that made the Holocaust so effective. As Bauman (1989: 90) points out, "rage and fury are pitiably primitive and inefficient as tools of mass annihilation. (...) One cannot build grand designs on them. (...) It is the practitioners of cold, thorough and systematic genocide like Stalin and Hitler for whom the modern, rational society paved the way". As this method of destruction relied on a systematic and rational approach instead of hatred, it were the ordinary people that the workings of the system relied on, not the fanatics or criminals. In fact, in most cases, during the trials of the Nazi mass mur- 
derers taking part in the extermination of the Jews and other groups, no mental aberrations were discovered. On the contrary, the people on whom the efficiency of the Holocaust depended were typically either the cultural and intellectual élite of their time, or the ordinary individuals, in no way morally or intellectually superior or inferior to the rest of society (Bauman 1989: 19). Finally, what is perhaps most disturbing is fact that the factors that contributed to the occurrence of the Holocaust and all the characteristics of the contemporary society that made it possible are still very much a part of every-day life and, therefore, it cannot be assumed that the risk of a phenomenon resembling the Holocaust happening again has been eliminated.

\section{The grotesque as a tool to describe the post-Holocaust reality in Cohen's art}

According to Wynands (2000: 203), both the language and the attitude of the speaking persona in Cohen's Flowers for Hitler are suitable for the description of the subject matter of the poems, which is the Holocaust. As she points out, "[the] knowledge of the ubiquity of evil results in a reversal of conventional aesthetics" and thus, exploring the ugliness, brutality, absurdity of the contemporary life, as well as failure, "[t]he poems (...) present a series of disparate, surreal glimpses of scenes that revel in the grotesque, the senseless, the tasteless". A similar technique is used in Beautiful Losers, in which, according to Ravvin (1993), the symbolics of the Holocaust acts as a "handy metaphor that stands in for numerous other kinds of extremity and human suffering". Ravvin sees the events of the Second World War as the shaping factors for Cohen's ouvre, inasmuch as, in his opinion, the artist explores the post-Holocaust psyche of modern man. Furthermore, contrary to what Pezzarello (1997: 12) states about the lyrical "I" distancing himself from the scenes that he describes and hiding behind a pose or a mask, Wynands (2000: 198) argues that the speaking persona appears to be in a position of "potential personal involvement." Also the use of the grotesque and creating the "world of aesthetic and moral inversions" (Wynands 2000: 203) is characteristic of those from Cohen's works that are concerned with the extermination of the Jews and other nations or groups, for instance the Indians in Beautiful Losers.

The exploration of the "grotesque" and "tasteless", to quote Wynands, is visible in the poem "A Migrating Dialogue" from Flowers for Hitler, in which a Nazi constable is "travelling abroad with a companion after the war to flee prosecution by the allied forces" (Wynands 2000: 204). The poem begins with the line: "He was wearing a black moustache and leather hair. We talked about the gypsies". The presence of the man with a moustache, undoubtedly, alludes to Hitler; the description of his "leather hair", in addition, resembles a similar portrayal from Beautiful Losers, where "Hitler of pornographic movies and trash novels" (Ravvin 1993) made his 
appearance, wearing "the old raincoat and mustache, but underneath (...) perfectly nude" (BL 1993: 93). The poem then proceeds: "Peekaboo Miss Human Soap (...)/ O blond S.S/ (...) I believe in gold teeth/ (...) Napoleon was a sexy brute". The references to "human soap" and "gold teeth" point at the atrocities performed on the bodies of dead prisoners in concentration camps. Then, in a way that Wynands (2000: 205) calls disrespectful, the person speaking in the poem discourages his companion from analyzing the atrocities committed during the war with the words: "I think we should let sleeping ashes lie", which of course is a playful and ironic allusion to the burning of the corpses of the Jews and other inmates from death camps. However, such portrayal of the issues related to the Holocaust and to the problem of victimization of every kind is present not only in Flowers for Hitler but also in Beautiful Losers. It can be argued, for instance, that food-related imagery is described in a tasteless and grotesque way as well, since, as Hutcheon (1974: 45) points out, "[t]he vision of Nazi torture (...) pervades Beautiful Losers: meat-eating humans are "dietary Nazis" with their Dachau farmyards". To conclude, when it comes to the reasons behind such a portrayal of the issues connected with the Holocaust, it is safe to assume that by applying absurd metaphors and images, Cohen is not "having a nasty laugh at the expanse of Jewish suffering", but it should be rather viewed as "an attempt to come to terms with a painful experience" and "present horror as an absurdity" (Djwa 1967: 40).

\section{The Holocaust as a product of the (post-)industrial society}

In a scene in Beautiful Losers where the Historian is visiting a factory belonging to F., his friend starts his monologue: "F. began to orate. He loved to talk against mechanical noise. - Larry! he cried, moving down the empty benches. Larry! Ben! Dave! I know you can hear me! Ben! I haven't forgotten your hunched back! Sol! I've done what I promised! (...) Jews, Jews, Jews! Thanks! (BL 1993: 24). F. then states that "[e]very generation must thank its Jews (...) [a]nd its Indians" (BL 1993: 24). Viewing the Holocaust as, in a way, a continuation of the process of extermination and exploitation started already by the massacre of the North American Indians corresponds with Bauman's (1989) views on the Holocaust as the phenomenon born out of the rationalization of the process of extermination. Also the phrase that F. "loved to talk against mechanical noise" gains a symbolic meaning when analysed in the context of Bauman's ideas, inasmuch as he argues that the Holocaust phenomenon was, first and foremost, the product of the modern, (post-)industrial society. As he points out: "Modern civilization was not the Holocaust's sufficient condition; it was, however, most certainly its necessary condition. Without it, the Holocaust would be unthinkable. It was the rational world of modern civilization that made the Holocaust thinkable" (Bauman 1989: 13). According to Bauman, without an efficient 
chain of concentration camps, which in fact can be seen as "factories" of a kind, the whole procedure of the structured and well-planned mass murder could not have been conducted. As he observes, "mass murder on an unprecedented scale depended on the availability of well-developed and firmly entrenched skills and habits of meticulous and precise division of labour, of maintaining a smooth flow of command and information" (Bauman 1989: 15). Hence, although F.'s phrasing may seem grotesque and hyperbolic, Cohen's novel in fact points at the same dangers of the contemporary Western society as those presented by Bauman.

One of other vital scenes in Beautiful Losers that link the novel's outlook on modern civilization with Bauman's views is the one in which Hitler appears as a waiter in a hotel room in Argentina, "wearing the old raincoat and mustache, but underneath (...) perfectly nude" (BL 1993: 93). In this part of the novel, F. and the Historian's wife fly to Argentina "for a little sun and experiments" and because the woman "was having trouble with her body: it kept changing sizes, she even feared that it might be dying" (BL 1993: 84). Here, even the phrase "it might be dying" suggests that the body is a separate part of a human being; the alien and to some extent hostile one. As a remedy to Edith's problems, F. decides to use on her the Danish Vibrator which eventually gets a life of its own, "learn[s] to feed itself" (BL 1993: 91) and then escapes through the window, making its "curiously graceful progress toward the Atlantic" (BL 1993: 92). What Ravvin (1993) calls an "outrageous bedroom scene" is followed almost immediately by Hitler's appearance. As Ravvin (1993) points out, the introduction of the Danish Vibrator - a piece of machinery - can be thus viewed as the prelude for the Hitler scene. He is "Hitler of pornographic movies and trash novels" (Ravvin 1993) and F. admits that he and Edith "hardly cared to resist his sordid exciting commands, even when he made [them] kiss the whip" (BL 1993: 93). Even more importantly, before he engages in a sexual encounter with the couple, he realises that they, as if, "prepared" (BL 1993: 93) for his visit by using the vibrator. Again, this remark corresponds with Bauman's opinion that mechanization and dehumanization led directly to the atrocities performed by the Nazi. Moreover, the fact that F. and Edith did not engage in a traditional sexual act but used a piece of machinery makes their intimacy more "sterile" and stresses what Bauman (1989: 96) calls "the symbolic expression (...) of the sanctity of human body" as understood in the contemporary Western society, along with the special care "which is taken not to invade that most private of spaces, to avoid bodily contact". As he points out, "[m] odern civilization can afford the fiction of the sanctity and autonomy of the human body thanks to the efficient mechanisms of self-control it has developed (...). Privacy of the body underlines personal responsibility for its behaviour, and thus adds powerful sanctions to the bodily drill".

In the final moments of the Hitler scene, "the waiter" hands to F. and Edith a bar of human soap and bathes with them. The symbolics of the soap seems also to be of great importance, insofar as, according to Ravvin (1993), it illustrates that modern 
society "turns humans into the vital material by which [it] justifies its own existence". On the other hand, as it was presented earlier, the symbolics of the soap, especially within the context of Jewish religious rites, may be viewed as a metaphor for cleansing of the body and, by extension, the human being as a whole, inasmuch as the ritual bathing and oiling function as the symbols of purification and sanctification before the celebration of the Sabbath and other Jewish ceremonies. Thus, it can be argued that again, typically for Cohen, the spheres of sacrum and profanum, as well as the lines between what is acceptable and what is blasphemous cease to be distinguished.

\section{The banality of evil}

As it was already mentioned, one of the most disturbing elements of the Holocaust, according to Bauman (1989: 19-22), is the fact that although it would be convenient to portray the Nazi perpetrators of the mass murder as abnormal and distinguishable from the rest of society, in reality, in most cases they were just ordinary people. This paradox is best presented in Cohen's poem "All There Is to Know about Adolph Eichmann" (Flowers for Hitler, 1976), which pertains to one of the major organizers of mass deportations of the Jews to concentration camps, who is believed to have been personally responsible for the deaths of a great number of Jews persecuted during the World War II. Interestingly, in her book based on Eichmann`s trials, Arendt (1964: 134) discusses him in the context of "the banality of evil". As she points out, "Eichmann was (...) not Macbeth [and] [e]xcept for an extraordinary diligence in looking out for his personal advancement, he had no motives at all". She also observes that "with the best will in the world one [could not] extract any diabolical or demonic profundity from Eichmann". Indeed, in his poem, Cohen describes him in such a way: "Eyes...Medium/ Hair...Medium/ Weight... Medium/ Height...Medium/ Distinguished features...None/ Number of fingers... Ten/ Number of toes...Ten/ Intelligence...Medium". The next part of the poem, however, poses a wry and ironic question: "What did you expect? Talons? Oversize incisors? Green saliva? Madness?". Again, what is stressed is the fact that it does not take an exceptionally gifted, devious, or otherwise extraordinary individual to act as a part of an inhuman system and that every person, however nondescript, may become potentially involved in its workings. The same problem is discussed in Cohen's debut novel, when Breavman reminisces on the war:

The Japs and Germans were beautiful enemies. They had buck teeth or cruel monocles and commanded in crude English with much saliva. They started the war because of their nature. (...) Best of all, they tortured. To get secrets, to make soap, to set examples to towns of heroes. But mostly they tortured for fun, because of their nature (FG 2000: 9). 
Once again, although it is easier and more convenient to imagine the Nazi and their allies as grotesque and their inhuman behaviour as motivated by their abnormality, the truth is more terrifying, insofar as, in fact, the totalitarian systems are dependent on ordinary people. In The Favourite Game, however, there is also an ambiguous dialogue between Breavman and Krantz concerning different forms of torture practiced during the war by both sides of the conflict:

- Germans used a lot of water in their tortures. They'd shove a hose up a guy's arse-hole to make him talk. - Great, Krantz. Japs had something like that. They'd make a guy eat a lot of uncooked rice then he'd have to drink a gallon of water. The rice would swell and--Yeah, I heard that one. - But, Krantz, want to hear the worst one? And it was the Americans who did it. Listen, they catch a Jap on the battlefield and make him swallow five or six rifle cartridges. Then they'd make him run and jump. The cartridges'd rip his stomach apart. He'd die of internal haemorrhage. American soldiers. - How about tossing babies in the air for bayonet practice? - Who did that? - Both sides. - That's nothing, Krantz, they did it in the Bible. 'Happy will they be who dash their little ones against the rock' (FG 2000: 38).

As this fragment illustrates, the boys reach a conclusion that both sides of a conflict are capable of cruelty. What is even more interesting, however, is Breavman's allusion to the Bible, inasmuch as, once again, it illustrates in a playful way the ambivalence that he feels towards his heritage.

\section{The emergence of the "New Jew"}

The last part of the aforementioned dialogue between Breavman and Krantz, with its conclusion that "they did it in the Bible" and the line "Happy will they be who dash their little ones against the rock" (FG 2000: 38) can be argued to allude to Psalm 137, in which the psalmist refers to the conquest of Jerusalem by the ancient Babylonians and the following period in Jewish history called the Babylonian captivity; the times of, as Gunkel (1903: 291) puts it, "full of misery and distress", but also the outburst of "a passion of ardent patriotism". The psalm states:

(...) If I forget thee, O Jerusalem/ Let my right hand fail/ Let my tongue clave to the roof of my mouth/ If I remember thee not/ If I set not Jerusalem/ Above my chief joy./ Remember it, Yahweh, against the children of Edan/ How, in the day of Jerusalem's destruction/ They said: "Destroy the city, destroy it/ Even to the foundation"./ O daughter of Babylon, thou destroyer/ Happy he who repays thee!/ Happy he who takes and dashes/ Thy children against the rock! (Psalm 137: 5-9)

As it can be seen, not only does the poet curse the oppressors of Jerusalem but also himself and possibly his people in case they ever forget the land they left. 
Gunkel (1903: 292) sums up the psalmist's message in these words: "However prosperous and happy my circumstances personally, I will not rejoice nor exult, I will remember the misery of Jerusalem". As it will be illustrated later, in the context of the whole novel, it seems vital that Cohen chose specifically this passage from the Bible, inasmuch as the contrast between the psalm's message and self-questioning present in The Favourite Game as for one's identity as a Jew can aim at further self-mockery.

Both in Beautiful Losers and The Favourite Game, one of the major topics is the issue related to the ambiguous Jewish identity and the emergence of the so-called "New Jew" (BL 1993: 82). As it has been already mentioned, the post-war period brought significant changes for the Jewish communities, especially in the North America, in regard to the changes in lifestyle and religiosity. However, in Cohen's works, one can frequently find the criticism towards these changes, as they can be argued to have impoverished Jewish spirituality and culture. In Beautiful Losers this new model of a Jewish person is depicted in such a way:

Who is the new Jew? The New Jew loses his mind gracefully. He has induced amnesia by a repetitious study of history, his very forgetfulness caressed by facts which he accepts with visible enthusiasm. He changes for a thousand years the value of stigma, causing men of all nations to pursue it as superior sexual talisman (BL 1993: 82).

As can be seen, the Jewishness ceases to be connected with the national or religious identity; on the contrary, it becomes a shallow, but otherwise fashionable and desirable concept that makes one's heritage seem more profound and attractive. The issue of the ambiguous national and religious identity is expressed also by the question that Breavman asks himself: "Weren't they supposed to be a holy people consecrated to purity, service, spiritual honesty?" (TFG 2000: 37). It is the allusion to the idea expressed in the Old Testament that the Jews are God's chosen people; however, Breavman's question shows the disillusionment with what the contemporary Jewish identity represents.

The problems related to the concept of identity are discussed also in The Favourite Game. Here, the protagonists, who are coming-of-age boys from the upperclass Jewish families from Montreal, are portrayed as being both "inside" and "outside" the Jewish world. Surrounded on the one hand by families similar to theirs and, on the other hand, by the Christian majority, they struggle to define their identity. This struggle is visible in a humorous dialogue between the main character, Lawrence Breavman, and his friend, Krantz: "- Krantz, is it true that we are Jewish? - So it has been rumoured, Breavman. - Do you feel Jewish, Krantz? - Thoroughly. - Do your teeth feel Jewish? - Especially my teeth, to say nothing of my left ball" (TFG 2000: 37). However, the ambiguity as far as the belonging to a given community is concerned is portrayed also in a more serious way in a scene where the boys spend the afternoon in the place that mainly non-Jews visit: 
The dancers were Catholics, French-Canadian, anti-Semitic, anti-Anglais, belligerent. They told the priest everything, they were scared by the Church (...). Everyone of them worked for a Jewish manufacturer whom he hated and waited for revenge. They had bad teeth because they lived on Pepsi-Cola and Mae West chocolate cakes. The girls were either maids or factory help. Their dresses were too bright and you could see bra straps through the flimsy material. Frizzy hair and cheap perfume. They screwed like jack rabbits and at confession the priest forgave them. They were the mob. Give them a chance and they'd burn down the synagogue ( $F G$ 2000: 40).

What can be seen from this description is the contempt that the boys feel for people from outside of the Jewish community, but it is also stated that the hostility is mutual. Moreover, since Breavman and Krantz do not interact frequently with the French-Canadians, their opinions are based to some extent on prejudices. These prejudices, however, are deep-rooted, as can be illustrated by the words: "Breavman and Krantz knew their parents were bigots so they attempted to reverse all their opinions. They did not quite succeed" (FG 2000: 40). In the light of this, it can be argued that Cohen, apart from commenting upon the degradation of the Jewish values and posing questions about the meaning of cultural identity in the contemporary world, is concerned also with the issue of coexistence of different cultures alongside one another.

Returning to the hypothesis posed at the beginning of this paper, it is now possible to conclude that what prevails in the works of Leonard Cohen is the state of ambivalence and ambiguity in relation to the issues connected with Judaism. Although the links and allusions to Judaism made by Cohen have been frequently stressed by the critics, what is demonstrated here is the fact that for Cohen, his Jewish heritage has not only been a source of inspiration but also doubt and anger. The irony adopted to describe the "dying myths" can be viewed as the reassessment of Cohen's identity and cultural inheritance. As for the issue of the Holocaust and its relevance for the future generations that has been also explored, it can be assumed that Cohen, similarly to Bauman, chooses to perceive the Holocaust not as a disturbing event for the Jewish community alone, but rather as an event that perfectly illustrates the "posthuman" condition of the contemporary society, which makes this event even more damaging.

\section{References}

Arendt, H. 1964. Eichmann in Jerusalem. New York: The Viking Press.

Bauman, Z. 1989. Modernity and the Holocaust. Ithaca, N.Y.: Cornell University Press.

Cohen, L. 1993. Beautiful losers. New York: Vintage Books.

Cohen, L. 1976. Flowers for Hitler. London: Jonathan Cape Ltd.

Cohen, L. 2000. The favourite game. Toronto: McClelland and Stewart.

Djwa, S. 1967. "Leonard Cohen. Black romantic". Canadian Literature 34. 32- 42. 
Gillman, N. 2004. “Contemporary Jewish theology”. W zbiorze: Neusner, J. and Avery-Peck A. J. (red.). The Blackwell companion to Judaism. Oxford: Blackwell Publishing. 441-460.

Gunkel, H. 1903. "Psalm 137: an interpretation". The Biblical World 22 (4). 290-293.

Hutcheon, L. 1974. "Beautiful losers: all the polarities". Canadian Literature 59. 42-56.

Hutcheon, L. 2001. The politics of postmodernism. New York: Routledge.

Lang, B. 2007. "Evil, suffering, and the Holocaust". W zbiorze: Morgan M. and Gordon P. E. (red.). The Cambridge companion to modern Jewish philosophy. Cambridge: Cambridge University Press. 277-299.

Morgan, M., Gordon P. E. (red.). 2007. The Cambridge companion to modern Jewish philosophy. Cambridge: Cambridge University Press.

Neusner, J. 2006. Judaism. The basics. New York: Routledge.

Neusner, J. and Avery-Peck A. J. 2004. The Routledge dictionary of Judaism. New York: Routledge.

Neusner, J. and Avery-Peck A. J. 2004. The Blackwell companion to Judaism. Oxford: Blackwell Publishing.

Pezzarello, Ch. J. 1997. "You have sweetened your word": sincerity and prayer in Leonard Cohen's book of mercy. Montreal: McGill University.

Ravvin, N. 1993. "Writing around the Holocaust: uncovering the ethical centre of "Beautiful losers". Canadian Poetry 33 (http://canadianpoetry.org/volumes/vol33/ravvin.html).

Salkin, J. K. 2004. "New Age Judaism”. W zbiorze: Neusner, J. and Avery-Peck A. J. 2004. The Blackwell companion to Judaism. Oxford: Blackwell Publishing. 352-370.

Scobie, S. (red.). 2000. Intricate preparations: writing Leonard Cohen. Toronto: ECW Press.

Wayman, T. 1974. "Cohen`s women”. Canadian Literature 60. 89-93.

Wynands, S. 2000. "The Representation of the Holocaust in Flowers for Hitler". W zbiorze: Scobie S. (red.). Intricate preparations: writing Leonard Cohen. Toronto: ECW Press. 198-209. 